\title{
La calidad y evaluación de las revistas científicas a debate: una mirada desde las Ciencias de la Actividad Física y el Deporte (Javier Valenciano-Valcárcel y José Devís-Devís, coords.)
}

\author{
Por Adolfo Alonso-Arroyo
}

\begin{abstract}
Alonso-Arroyo, Adolfo. "La calidad y evaluación de las revistas científicas a debate: una mirada desde las Ciencias de la Actividad Física y el Deporte (Javier Valenciano-Valcárcel y José Devís-Devís, coords.)”. Reseña de libro. El profesional de la información, 2010, mayo-junio, v. 19, n. 3, pp. 317-318.

DOI: 103145/epi.2010.may.15
\end{abstract}

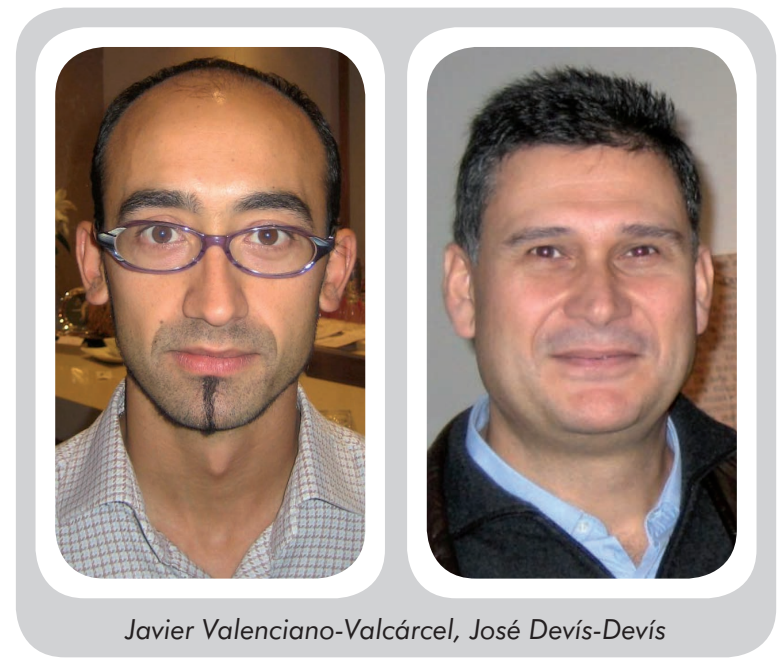

guía. Expone la evolución positiva que han tenido estas publicaciones atendiendo a su calidad formal, de contenido y a su difusión, cada vez más visible en recursos electrónicos, internet o bases de datos internacionales, aunque aún están lejos de otras áreas del conocimiento.

Plantea estrate-

LAS REVISTAS CIENTÍFICAS siguen teniendo un papel clave en el avance de la ciencia y en la transmisión de información, pues aunque cada vez existen más mecanismos para comunicar la ciencia, las revistas siguen considerándose el instrumento por excelencia.

Pero, ¿tienen calidad estas revistas científicas? Diferentes especialistas en la materia dan a conocer en este libro una visión de la situación de su calidad. Aunque se refieren a las de ciencias de la actividad física y el deporte, sus hallazgos pueden relacionarse o contrastarse con otras disciplinas, y ser igualmente válidos.

La obra recoge mejoras y deficiencias de la calidad de las publicaciones en un área joven, pero en auge, lo que la convierte en una gias para mejorar la calidad de las revistas españolas del área, y pautas para solventar las lagunas actuales como la normalización de las revistas o la adopción del sistema de revisión por pares.

"Las revistas aún son el principal medio de difusión de la ciencia"

El hecho de haber incluido expertos procedentes de Inglaterra añade valor a la publicación. Entre los autores hay que destacar la participación de editores de revistas de prestigio en el área del deporte: David Kirk, de la revista Physical education and sport pedagogy, Alan M. Nevill, del Journal of

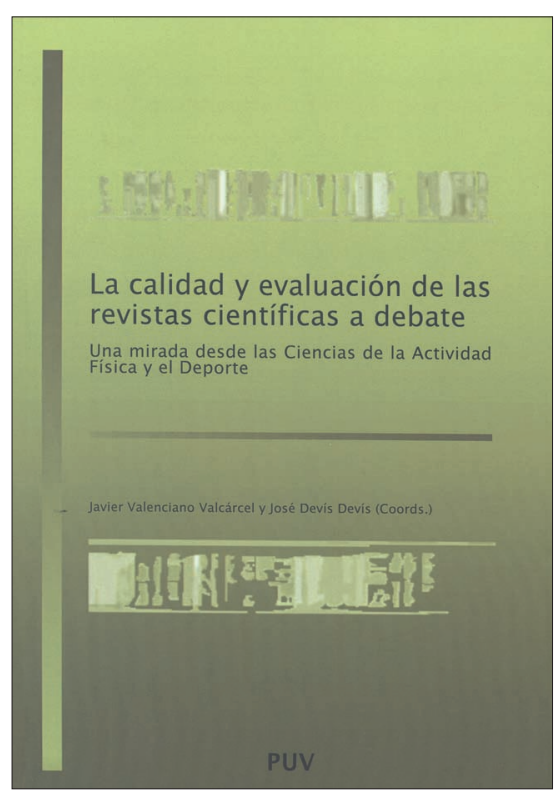

Valenciano-Valcárcel, Javier; Devís-Devís, José (coords.). La calidad y evaluación de las revistas científicas a debate: una mirada desde las Ciencias de la Actividad Física y el Deporte. Valencia:

Publicacions de la Universitat de València (PUV), 2010. $114 \mathrm{pp}$.

ISBN 978-84-370-7685-0

sports sciences y Ken Green editor de la European physical education review. Ellos ofrecen una perspectiva diferente de los criterios de evaluación de las revistas científicas. 
Aunque no cuestionen los indicadores vinculados al análisis de citas, sí hacen ver que no son los únicos. Ofrecen alternativas a tener en cuenta como el uso de la lista de distribución y diagrama de flujos de la declaración Consort, diseñados para escribir, revisar o evaluar informes de ensayos clínicos controlados pero que bien pueden aplicarse a artículos científicos de cualquier ámbito de la ciencia.

Y también incluyen el análisis de citas que ofrecen otras fuentes de citación como Google Scholar y Scopus (Scimago Journal Rank) que estiman necesarios para hacer un juicio de calidad ponderado.

En definitiva, consideran que los editores son los responsables últimos de la excelencia de una revista y que si mantienen un alto nivel de control de los principios metodológicos, cuentan con el apoyo de los revisores y la concienciación por parte de los autores, están seguros de que cualquier revista podría conseguir una calidad digna.

\section{"La calidad de las revistas científicas se debe obtener de la combinación de múltiples indicadores y no sólo del Factor de impacto"}

En un plano diferente, David Brown da una visión de tipo cualitativo que está más alejada de lo que en España conocemos. Recoge estrategias de los análisis de citas y el Factor de impacto (IF) pero desde un prisma subjetivo y práctico. No sólo toma en consideración los indicadores per se, sino que contempla otros aspectos como las emociones y las creencias de los investigadores. Por tanto, propone que la investigación sea evaluada no sólo mediante el clásico peer-review doble ciego, sino también por compañeros de nuestro ámbito de estudio, quienes son los que pueden profundizar realmente en la excelencia o no de un trabajo. Así por ejemplo plantea que se debata la calidad de un artículo dependiendo del tipo de cita recibido. Y es que publicar en la revista adecuada y para un público apropiado fomenta que su repercusión e impacto sea real. Estos indicadores reflejarían para el autor el impacto práctico y los presenta como otra alternativa para conseguir un trabajo de calidad.

Como muchos investigadores indicamos, sobre todo desde el ámbito de las ciencias sociales y las humanidades, los análisis cuantitativos de citas en revistas científicas siguen siendo limitados para evaluar nuestras áreas. Además de los sesgos idiomáticos, bien conocidos por todos, el impacto de un trabajo no está suficientemente reflejado debido a unos patrones de consumo y reconocimiento diferentes a los de las ciencias duras o biomédicas.

La metodología que plantea el autor puede ser un principio para superar esta tradicional crítica a los indicadores de tipo cuantitativo, cuyos datos provienen de WoS y Scopus principalmente. Complementar los estudios cienciométricos con estos análisis de tipo cualitativo aportaría además indicios de la verdadera transferencia de conocimiento en su ámbito de influencia.

Otros temas que trata la obra son la digitalización y el libre acceso. Dos aspectos que aunque no son determinantes en cuanto a la calidad de una publicación científica sí pueden ayudar a adquirir un mayor reconocimiento y visibilidad. Así también algún autor plantea el uso crítico del factor de impacto $(I F)$, la necesidad de elaborar índices de citas propios y algunas recomendaciones para evitar errores y reducir el esfuerzo a quien quiera aventurarse en la publicación de una revista científica de calidad.

El hecho de estar enfocado a un área determinada, ciencias de la actividad física y deporte, permite apreciar que los parámetros y niveles de evaluación no pueden ser siempre únicos y uniformes. Sin dejar de lado el rigor científico con que evaluar la calidad, el libro da cuenta de que deben tenerse también en consideración otros, como el área de conocimiento, el ámbito geográfico y cultural.

Es sin duda un libro muy recomendable para los editores y responsables de las publicaciones científicas, para los posibles autores de las mismas y para organismos encargados de la evaluación de la actividad investigadora.

Adolfo Alonso-Arroyo es licenciado en documentación por la Univ. de Granada, doctor en documentación por la Univ. Politécnica de Valencia, y profesor en la Universidad de Valencia.

Facultad de Medicina y Odontología, Departamento de Historia de la Ciencia y Documentación.

Avda. Blasco Ibáñez 15, 46010 Valencia. adolfo.alonso@uv.es 